\title{
Evaluation of Serum and Aqueous Humor Vascular Endothelial Growth Factor in Neovascular Glaucoma
}

\author{
Waled Mahdy Nada1, Doaa Attia Abdel-Moety² \\ ${ }^{1}$ Ophthalmology Department, Faculty of Medicine, Zagazig University, Zagazig, Egypt \\ ${ }^{2}$ Physiology Department, Faculty of Medicine, Zagazig University, Zagazig, Egypt \\ Email:walednada_69@hotmail.com,daabdelmoeti@zu.edu.eg
}

How to cite this paper: Nada, W.M. and Abdel-Moety, D.A. (2017) Evaluation of Serum and Aqueous Humor Vascular Endothelial Growth Factor in Neovascular Glaucoma. Open Journal of Ophthalmology, 7, 79-87.

https://doi.org/10.4236/ojoph.2017.72012

Received: March 10, 2017

Accepted: May 15, 2017

Published: May 18, 2017

Copyright $\odot 2017$ by authors and Scientific Research Publishing Inc. This work is licensed under the Creative Commons Attribution International License (CC BY 4.0).

http://creativecommons.org/licenses/by/4.0/

(c) (†) Open Access

\begin{abstract}
Purpose: The study aimed to evaluate and correlate between the levels of vascular endothelial growth factor (VEGF) in serum and aqueous humor in cases of neovascular glaucoma (NVG) to stand up on if it can be used as a marker for early detection of such cases. Methods: This observational case control study included 60 eyes, divided into 3 groups, group A of 30 eyes presented by cataract of different causes (not diabetic patients and no signs of NVG) as a control group and group B of 30 eyes with NVG due to different causes, group $\mathrm{C}$ of the same eyes in group $\mathrm{B}$ but after one month of treatment by intravitreal bevacizumab and laser treatment by pan retinal photocoagulation (PRP). Serum VEGF was estimated in all groups, also aqueous humor VEGF was estimated in group A and B only. In addition glycosylated hemoglobin (HbAlc) was estimated in group B; statistical analysis of the results was performed. Results: The study revealed that the commonest cause of NVG was proliferative diabetic retinopathy (PDR) in 26 cases (86.7\%), HbA1c in group B revealed mean value $7.68 \% \pm 2.75 \%$. Serum VEFG level in the group $\mathrm{B}$ of cases of NVG was significantly higher than the control group A $(\mathrm{P}<$ 0.001 ), and moderate significantly lower than group C of treated NVG by intravitreal bevacizumab injection and PRP $(\mathrm{P}<0.05)$. Also aqueous VEGF level in group $B$ was increased significantly from control group A $(P<0.001)$. In group $B$, the study reported a positive correlation between serum VEGF (S-VEGF) and aqueous humor VEGF (A-VEGF) levels $(\mathrm{r}=0.638)$ with a high significant result $(\mathrm{P}<0.001)$. Also, there was positive correlation between HbAlc and VEGF in serum $(r=0.409)$ with a moderate significant result $(\mathrm{P}<$ $0.05)$ But there was no correlation between HbAlc and VEGF in aqueous humor $(r=0.327)$ with an insignificant result $(P>0.05)$. Conclusions: VEGF is considered a good marker for the NVG either in serum or aqueous humor, laser treatment and the use of anti-VEGF are crucial treatment for such cases,
\end{abstract}


and also glycemic control is a must for regulation of the vascular process in diabetic patients for prevention of such ocular neovascularization.

\section{Keywords}

Vascular Endothelial Growth Factor (VEGF), Neovascular Glaucoma, Anti-VEGF, Diabetic Retinopathy

\section{Introduction}

Vascular endothelial growth factor (VEGF), as an endothelial cell-specific mitogen, it is liberated from the endothelial lining of the blood vessels in response to tissue ischemia in different parts in the body. It is the predominant factor in new vascular formation or neovascularization. Many studies evaluated the relationship between VEGF and different diseases in the body, some relations were not clarified. Since 1996, VEGF is considered one of the important factors that eliminated from the endothelial cells lining of the retinal capillaries in respond to ischemic retinal conditions leading to many ocular manifestations [1] [2] [3].

Neovascular glaucoma (NVG) is one the serious ocular conditions that facing ophthalmologists, resulting from liberation of VEGF secondary to ischemic retinal conditions such as proliferative diabetic retinopathy and retinal vein occlusion. The use of anti-VEGF is currently promising agent, supported by several studies suggesting better visual prognosis and good intraocular pressure (IOP) control following anti-VEGF injections [4] [5] [6].

Retinal laser treatment by pan retinal photocoagulation (PRP) is one of the important treatment strategies in management of NVG, the use of anti-VEGF agents as bevacizumab can also play a similar rule in such management. Many studies stated that the intraocular injection of bevacizumab either intravitreal or intracameral can achieve a good control of IOP in cases of NVG [7] [8] [9] [10].

Measuring of VEGF either in the serum or aqueous can be a good method in monitoring the neovascular processes in cases with ischemic retinal conditions especially diabetic ones. Many studies reported that serum and aqueous VEGF increased in cases of NVG and proliferative diabetic retinopathy (PDR). So it is considered a good angiogenesis indicator for the progression and regression of the neovascular process in such cases. But some studies stated that estimation of VEGF in aqueous humor was more accurate in association of ocular ischemia rather than serum level due to the affection of the serum level of VEGF by other ischemic conditions in the body especially in diabetic patients [11] [12] [13] [14].

The present study was performed to correlate between the level of VEGF in both serum and aqueous humor in cases with NVG without studying any other contributing factors in the body, in a trial for early laboratory detection of ocular new vessels formation which may be beneficial for early treatment and prevention of blindness. 


\section{Patients and Methods}

This observational case control study was performed at the Zagazig University Hospital, Egypt, from February 2016 to December 2016. The study was performed according to WMA Declaration of Helsinki-Ethical Principles for Medical Research Involving Human Subjects. A written consent was obtained after the study information was explained.

The study included randomly selected 60 eyes, divided into 3 groups, group A of 30 eyes presented by cataract of different causes (not presented by NVG) as control group and group B of 30 eyes with NVG due to different causes, group C of the same eyes in group B but after one month of treatment by intravitreal bevacizumab and laser treatment by PRP.

Criteria of selection of the control group A:

- Randomly selected patients with immature cataract of different causes preparing for cataract extraction.

- Non diabetic persons, by normal laboratory estimation of glycosylated hemoglobin (HbA1c) (below 6\%) and normal fasting blood glucose (below 110 mg \%).

- No signs of NVG (normal iris by slit lamp examination) and angle (by goldmann 3 mirror angle examination). Also no signs of PDR or retinal vascular occlusion (by indirect ophthalmoscopy in a dilated pupil).

Criteria of selection of group B:

- Patients with NVG due to different causes (By elevated IOP, Reobeosis iridis or iris neovascularization by slit lamp examination) or angle neovascularization by gonioscopy as in group A).

- Cases with PDR or retinal vein occlusion.

- Clear ocular media (cornea, lens and vitreous).

Criteria of group C:

- The same cases of group B with NVG.

- Cases were subjected to single dose of intravitreal of bevacizumab $0.05 \mathrm{ml}$ containing $1.25 \mathrm{mg}$ (Avastin $100 \mathrm{mg} / 4 \mathrm{ml}$, Roche Ltd, Basel), under aseptic conditions at ophthalmic operative room, followed after 2 weeks by retinal laser treatment, with 1000 - 1400 burns (in 2 or 3 sessions), $200-250 \mu \mathrm{m}$ spot size, and energy of 250 - 800 MW (Nidek double frequency Yag Laser GYC1000).

Group A, B were subjected to estimation of VEGF in aqueous humor sample $(0.05 \mathrm{ml}-0.1 \mathrm{ml})$ by anterior chamber paracentesis in control group A during cataract extraction by phacoemulsification and in group B of NVG cases after intravitreal bevacizumab injection using 28 gauge syringes under aseptic conditions at ophthalmic operation room. Samples were subjected to laboratory estimation of VEGF using Human VEGF Quantitative Elisa Kit (R\&D Systems a biotechne brand) assay range (31.2 - 2000 pg-mL). Also, HbAlc was estimated in cases of group B.

Serum level of VEGF in all groups was estimated via venous blood sample by the same kits, in the control group immediately before cataract surgery, in group 
B immediately before the intravitreal injection and in group $\mathrm{C}$ after one month of laser treatment and intravitreal injection of bevacizumab.

Data was collected and subjected to statistical analysis using One Way Anova and determination of $\mathrm{P}$ value $(\mathrm{P}>0.05$ insignificant $),(\mathrm{P}<0.05$ moderate significant), and ( $\mathrm{P}<0.001$ highly significant). Also paired $\mathrm{T}$ test was performed for statistical analysis of the levels of aqueous humor VEGF and $\mathrm{P}$ value determination.

\section{Results}

The demographic data in the control group A revealed that 18 (60\%) were male and $12(40 \%)$ were female. Age ranged from 29 to 65 years with a mean age of $(44.51 \pm 9.21)$ years. Group B, C revealed that $21(70 \%)$ were male and $9(30 \%)$ were female. Age of the patients ranged from 39 to 70 years with a mean age of (50.01 \pm 9.11$)$ years.

As regards to the causes of NVG in group B and C, PDR in 26 (86.7\%) cases and central retinal vein occlusion in 4 (13.3\%) cases.

Estimation of $\mathrm{HbAlc}$ in group $\mathrm{B}$ revealed that the mean value of $\mathrm{HbAlc}$ was $7.68 \% \pm 2.75 \%$.

Serum VEGF level in the group B of cases of NVG was (356.88 \pm 68.45$)$ pg-ml increased significantly from the control group A (112.54 \pm 65.13$)$ pg-ml $(\mathrm{P}<$ 0.001 ), and also differed significantly from group C of treated NVG by intravitreal bevacizumab injection and retinal laser treatment which revealed decrease in the level of VEGF but not reached to the level of the control group (232.65 \pm 56.65) pg-ml $(\mathrm{P}<0.05)$ moderate significant.

The study revealed that aqueous VEGF level in group B was (832.88 \pm 96.44$)$ pg-ml increased significantly from the control group A $(206.5 \pm 45.84)$ pg-ml $(\mathrm{P}<0.001)$ by paired $\mathrm{T}$ test, and reporting that the level of VEGF in aqueous humor was more higher than in serum and both were increased significantly than the control group (Table 1).

Table 1. The demographic and laboratory findings in all groups.

\begin{tabular}{|c|c|c|c|c|c|c|c|c|}
\hline & \multirow{3}{*}{ Age in years } & \multicolumn{4}{|c|}{ Sex } & \multirow{3}{*}{$\begin{array}{c}\text { HbAlc } \\
\%\end{array}$} & \multirow{3}{*}{$\begin{array}{l}\text { Serum } \\
\text { VEGF } \\
\text { pg-ml }\end{array}$} & \multirow{3}{*}{$\begin{array}{l}\text { Aqueous } \\
\text { VEGF } \\
\text { pg-ml }\end{array}$} \\
\hline & & \multicolumn{2}{|c|}{ Male } & \multicolumn{2}{|c|}{ Female } & & & \\
\hline & & No. & $\%$ & No. & $\%$ & & & \\
\hline Group A & $44.51 \pm 9.21$ & 18 & 60 & 12 & 40 & $<6$ & $112.54 \pm 65.13^{\star}$ & $206.5 \pm 45.84^{* * * *}$ \\
\hline Group B & $50.01 \pm 9.11$ & 21 & 70 & 9 & 30 & $7.68 \pm 2.75$ & $356.88 \pm 68.45^{\star \star}$ & $832.88 \pm 96.44^{\star * * * *}$ \\
\hline Group C & $50.01 \pm 9.11$ & 21 & 70 & 9 & 30 & ------- & $232.65 \pm 56.65^{\star * *}$ & ------------- \\
\hline $\begin{array}{l}\text { Statistical } \\
\text { Tests }\end{array}$ & & & & & & & $\begin{array}{c}\text { One Way Anova } \\
\mathrm{P}<0.001 \\
\text { high significant } \\
\text { between } * \text {, ** } \\
\mathrm{P}<0.05 \\
\text { moderate significant } \\
\text { between }{ }^{*}, * * *\end{array}$ & $\begin{array}{c}\text { Paired T test } \\
\text { between }{ }^{* * * *}, * * * * * \\
P<0.001 \text { High significant }\end{array}$ \\
\hline
\end{tabular}


In group $B$, the study reported a positive correlation between serum VEGF (S-VEGF) and aqueous humor VEGF (A-VEGF) levels $(r=0.638)$ with a high significant result $(\mathrm{P}<0.001)$ (Figure 1$)$.

Also, there was positive correlation between HbA1c and VEGF in serum $(r=$ 0.409) with a moderate significant result $(\mathrm{P}<0.05)$ But there was no correlation between $\mathrm{HbAlc}$ and VEGF in aqueous humor $(\mathrm{r}=0.327)$ with an insignificant result $(\mathrm{P}>0.05)$ (Figure 2 and Figure 3$)$.

\section{Discussion}

The present study was limited in correlation between the level of VEGF in both serum and aqueous humor in cases with NVG without studying any other contributing factors in the body. As new vessels formation may be developed secondary to tissue ischemia due to liberation of VEGF; these vessels may be beneficial in some parts of the body and may be harmful in some parts. Ocular neovascularization is considered one of the harmful problems facing ophthalmologist secondary to retinal ischemia, NVG is a serious ocular complication secondary to this ischemic process. Many studies as Pe'er et al. (1996) [3], Hsu et al. (2016) [15] and the present study aimed at early laboratory detection of ocular neovascularization before clinical detection in a trial for early treatment and saving for vision. This aim was achieved, as the present study reported a high significant increase in both serum and aqueous VEGF $(\mathrm{P}<0.001)$ in patients with NVG in comparison to the control group in agree with many studies as Tolentino et al. (1996) [2] and Mahdy et al. (2010) [11].

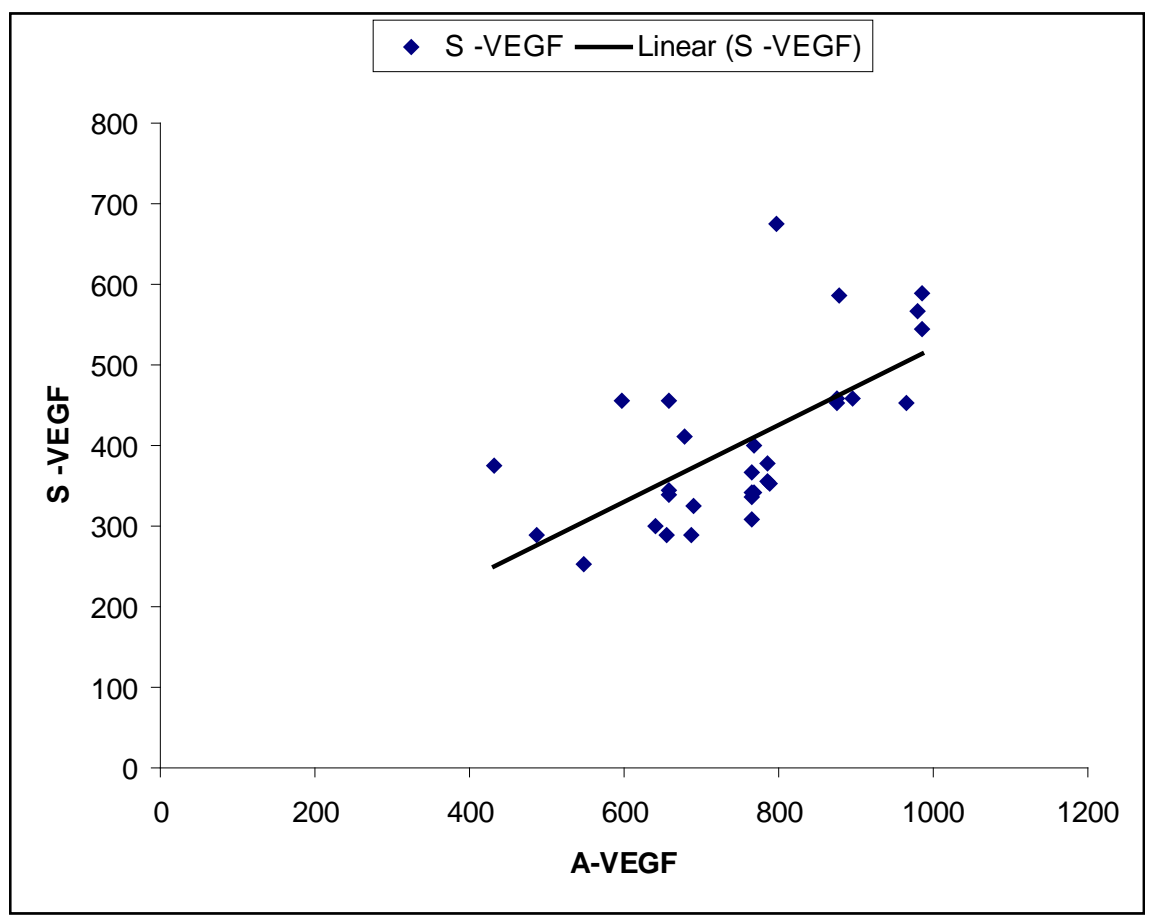

Figure 1. Correlation between serum VEGF (S-VEGF) and aqueous humor VEGF (AVEGF) levels (pg-ml) $(r=0.638)$ high significant $(\mathrm{P}<0.001)$. 


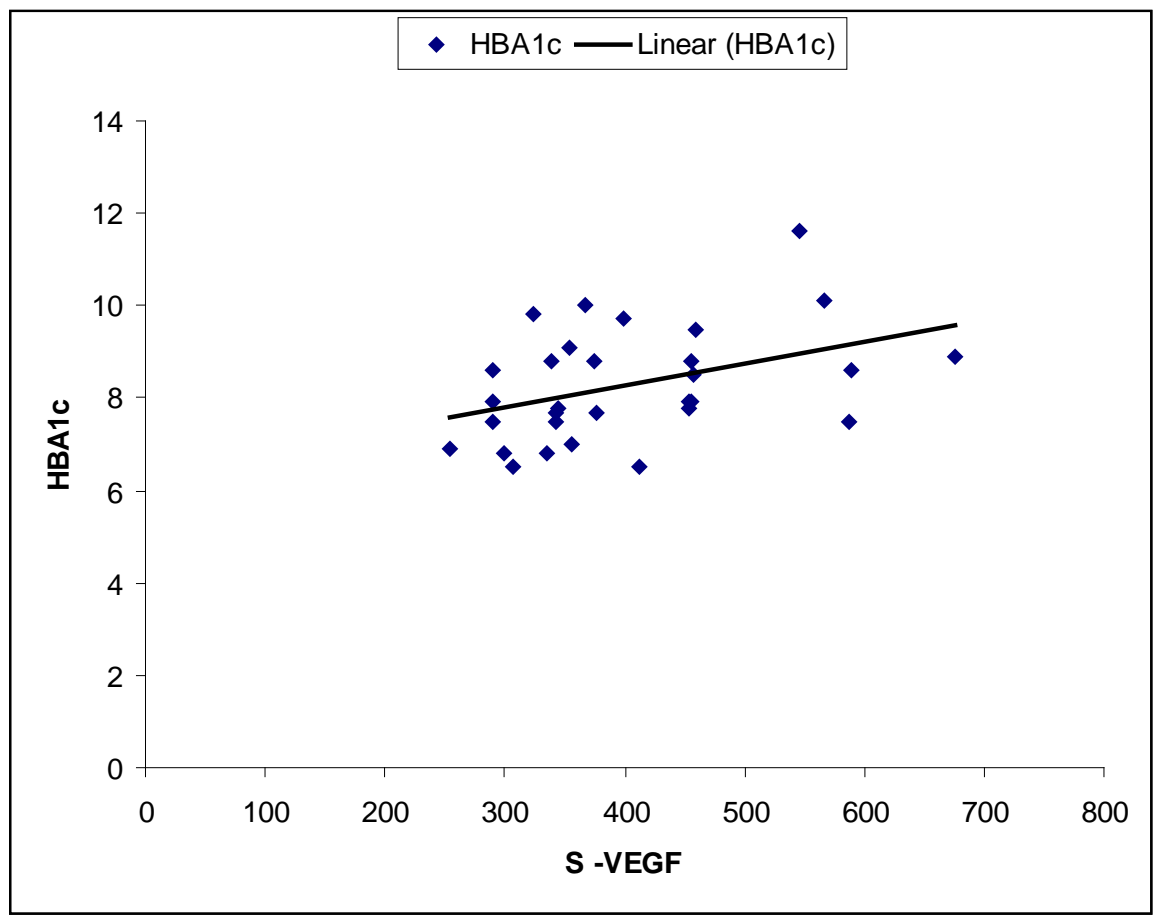

Figure 2. Correlation between HbA1c (\%) and serum VEGF (pg-ml) (S-VEGF) levels ( $\mathrm{r}=$ $0.409)$ moderate significant $(\mathrm{P}<0.05)$.

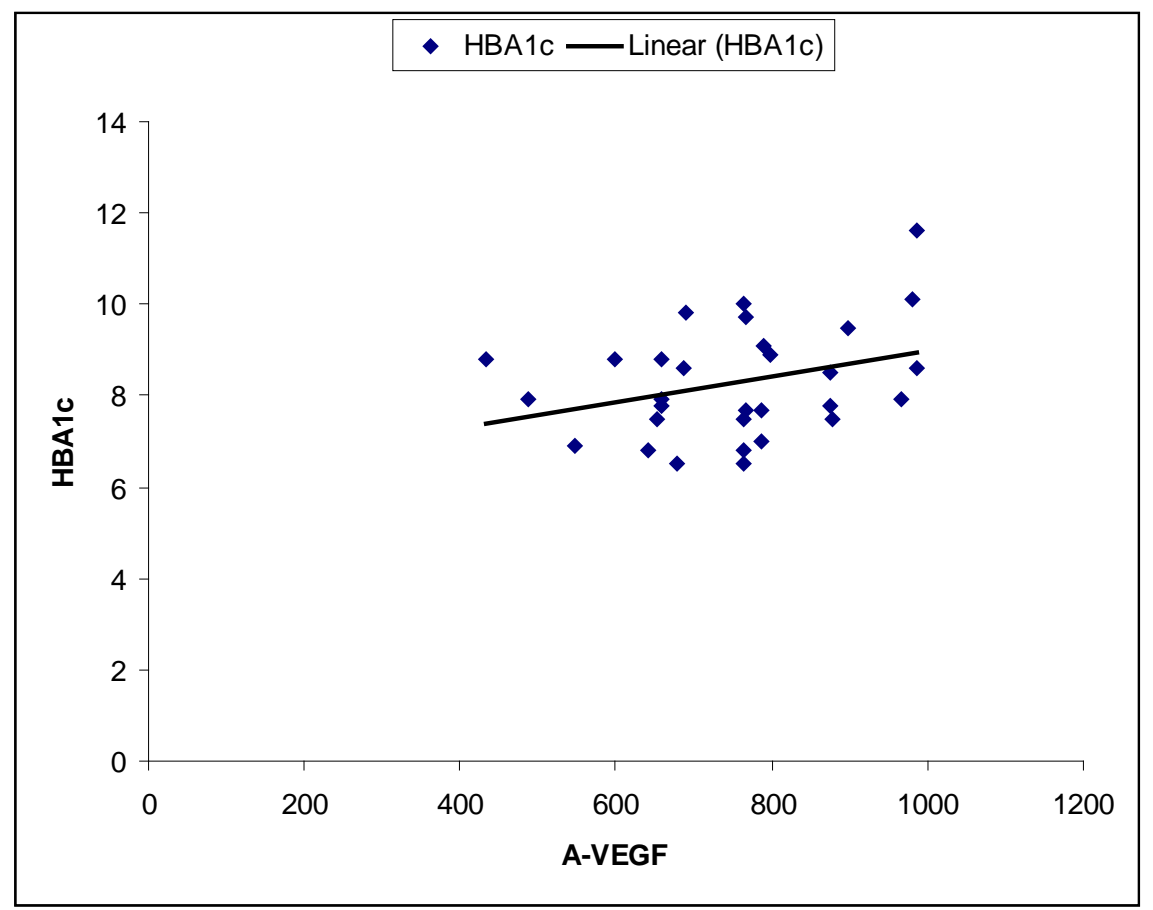

Figure 3. Correlation between HbA1c (\%) and aqueous humor VEGF (pg-ml) (A-VEGF) levels $(r=0.327)$ insignificant $(\mathrm{P}>0.05)$.

Diabetes mellitus is considered one of the main causes of vascular angiopathies all over the body. Either macro or micro angiopathies can induce tissue ischemia and hence liberation of VEGF for compensating angiogenesis. So some 
studies as Maier et al. (2006) [16] stated that estimation of the level of VEGF in the aqueous humor and vitreous is more accurate in detection of ocular neovascularization rather than the serum by according to their results, but the present study and many studies as Tolentino et al. (1996) [2], Pe'er et al. (1996) [3] and Mahdy et al. (2010) [11] agree in a conclusion that serum VEGF increased significantly in cases of ocular neovascularization. Also the present study reported a positive correlation between serum and aqueous level of VEGF in diabetic patients with NVG and also reported a significant decrease $(\mathrm{p}<0.05)$ in serum level of VEGF after laser treatment and intravitreal injection of bevacizumab and the study did not apply aqueous level estimation of VEGF after the treatment to minimize the hazards for the patients. These results agreed with many studies as Park et al. (2012) [5] and Wang et al. (2015) [4] who stated that retinal laser treatment and the use of anti-VEGF were a crucial treatment for NVG by the evidence of decrease in the level of VEGF either in serum or aqueous or vitreous. So that, all these results leading to the importance of regular estimation of serum VEGF can be a good monitoring for the neovascularization.

As regarding to the causes of NVG, the present study reported PDR in 26 (86.7\%) cases and central retinal vein occlusion in $4(13.3 \%)$ cases in agreement with the study of Liao et al. (2016) [17] who stated that Diabetic retinopathy was the commonest cause for NVG.

About the relation between the control of glucose blood level and VEGF, the present study reported that there was a positive correlation between $\mathrm{HbAlc}$ and VEGF in serum $(r=0.409)$ with a moderate significant result $(\mathrm{P}<0.05)$ But there was no correlation between HbAlc and VEGF in aqueous humor $(\mathrm{r}=$ $0.327)$ with an insignificant result $(\mathrm{P}>0.05)$ in agreement with Hanefeld et al. (2016) [18] who concluded the same results as regarding to the relation of serum VEGF and glycemic control in diabetic patients, the insignificant correlation between $\mathrm{HbAlc}$ and aqueous humor VEGF level may be dependent on other factors in relation to the aqueous blood barrier or other unknown factors.

\section{Conclusion}

VEGF is considered a good marker for the NVG either in serum or aqueous humor, laser treatment and the use of anti-VEGF are crucial treatment for such cases, and also glycemic control is a must for regulation of the vascular process in diabetic patients for prevention of such ocular neovascularization. Further studies about other specific angiogenic markers are needed for more evaluation of the ischemic process in diabetic patients.

\section{Conflict of Interest}

The authors declare no conflict of interest.

\section{References}

[1] Jazwa, A., Florczyk, U., Grochot-Przeczek, A., Krist, B., Loboda, A., Jozkowicz, A. and Dulak, J. (2016) Limb Ischemia and Vessel Regeneration: Is There a Role for 
VEGF. Vascular Pharmacology, 86, 18-30. https://doi.org/10.1016/j.vph.2016.09.003

[2] Tolentino, M.J., Miller, J.W., Gragoudas, E.S., Chatzistefanou, K., Ferrara, N. and Adamis, A.P. (1996) Vascular Endothelial Growth Factor Is Sufficient to Produce Iris Neovascularization and Neovascular Glaucoma in a Nonhuman Primate. Arch Ophthalmology, 114, 964-970. https://doi.org/10.1001/archopht.1996.01100140172010

[3] Pe'er, J., Folberg, R., Itin, A., Gnessin, H., Hemo, I. and Keshet, E. (1996) Upregulated Expression of Vascular Endothelial Growth Factor in Proliferative Diabetic Retinopathy. British Journal of Ophthalmology, 80, 241-245. https://doi.org/10.1136/bjo.80.3.241

[4] Wang, J.W., Zhou, M.W., Zhang, X., Huang, W.B., Gao, X.B., Wang, W., Chen, S., Zhang, X.Y., Ding, X.Y. and Jonas, J.B. (2015) Short-Term Effect of Intravitrealranibizumab on Intraocular Concentrations of Vascular Endothelial Growth Factor-A and Pigment Epithelium-Derived Factor in Neovascular Glaucoma. Journal of Clinical \& Experimental Ophthalmology, 43, 415-421.

[5] Park, S.C., Su, D. and Tello, C. (2012) Anti-VEGF Therapy for the Treatment of Glaucoma: A Focus on Ranibizumab and Bevacizumab. Expert Opinion on Biological Therapy, 12, 1641-1647. https://doi.org/10.1517/14712598.2012.721772

[6] SooHoo, J.R., Seibold, L.K. and Kahook, M.Y. (2013) Recent Advances in the Management of Neovascular Glaucoma. Seminars in Ophthalmology, 28, 165-172. https://doi.org/10.3109/08820538.2012.730103

[7] Yazdani, S., Hendi, K., Pakravan, M., Mahdavi, M. and Yaseri, M. (2009) Intravitrealbevacizumab for Neovascular Glaucoma: A Randomized Controlled Trial. Journal of Glaucoma, 18, 632-637.

[8] Wittström, E., Holmberg, H., Hvarfner, C. and Andréasson, S. (2012) Clinical and Electrophysiologic Outcome in Patients with Neovascular Glaucoma Treated with and without Bevacizumab. European Journal of Ophthalmology, 22, 563-574.

[9] Olmos, L.C., Sayed, M.S., Moraczewski, A.L., Gedde, S.J., Rosenfeld, P.J., Shi, W., Feuer, W.J. and Lee, R.K. (2016) Long-Term Outcomes of Neovascular Glaucoma Treated with and without Intravitrealbevacizumab. Eye (Lond), 30, 463-472. https://doi.org/10.1038/eye.2015.259

[10] Rodrigues, G.B., Abe, R.Y., Zangalli, C., Sodre, S.L., Donini, F.A., Costa, D.C., Leite, A., Felix, J.P., Torigoe, M., Diniz-Filho, A. and de Almeida, H.G. (2016) Neovascular Glaucoma: A Review. International Journal of Retina and Vitreous, 14, 2:26. https://doi.org/10.1186/s40942-016-0051-x

[11] Mahdy, R.A., Nada, W.M., Hadhoud, K.M. and El-Tarhony, S.A. (2010) The Role of Vascular Endothelial Growth Factor in the Progression of Diabetic Vascular Complications. Eye, 24, 1576-1584. https://doi.org/10.1038/eye.2010.86

[12] Chen, S., Zhou, M., Wang, W., Wu, H., Yu, X., Huang, W., Gao, X., Wang, J., Li, X., $\mathrm{Du}$, S., Ding, X. and Zhang, X. (2015) Levels of Angiogenesis-Related Vascular Endothelial Growth Factor Family in Neovascular Glaucoma Eyes. Acta Ophthalmologica, 93, e556-e560. https://doi.org/10.1111/aos.12624

[13] Tripathi, R.C., Li, J., Tripathi, B.J., Chalam, K.V. and Adamis, A.P. (1998) Increased Level of Vascular Endothelial Growth Factor in Aqueous Humor of Patients with Neovascular Glaucoma. Ophthalmology, 105, 232-237.

[14] Bleda, S., De Haro, J., Varela, C., Esparza, L., Ferruelo, A. and Acin, F. (2012) Vascular Endothelial Growth Factor Polymorphisms Are Involved in the Late Vascular Complications in Type II Diabetic Patients. Diabetes and Vascular Disease Research, 9, 68-74.

[15] Hsu, M.Y., Hung, Y.C., Hwang, D.K., Lin, S.C., Lin, K.H., Wang, C.Y., Choi, H.Y., 
Wang, Y.P. and Cheng, C.M. (2016) Detection of Aqueous VEGF Concentrations before and after Intravitreal Injection of Anti-VEGF Antibody Using Low-Volume Sampling Paper-Based ELISA. Scientific Reports, 6, 34631.

[16] Maier, R., Weger, M., Haller-Schober, E.M., El-Shabrawi, Y., Theisl, A., Barth, A., Aigner, R. and Haas, A. (2006) Application of Multiplex Cytometric Bead Array Technology for the Measurement of Angiogenic Factors in the Vitreous. Molecular Vision, 12, 1143-1147.

[17] Liao, N., Li, C., Jiang, H., Fang, A., Zhou, S. and Wang, Q. (2016) Neovascular Glaucoma: A Retrospective Review from a Tertiary Center in China. BMC Ophthalmology, 16, 14. https://doi.org/10.1186/s12886-016-0190-8

[18] Hanefeld, M., Appelt, D., Engelmann, K., Sandner, D., Bornstein, S.R., Ganz, X., Henkel, E., Haase, R. and Birkenfeld, A.L. (2016) Serum and Plasma Levels of Vascular Endothelial Growth Factors in Relation to Quality of Glucose Control, Biomarkers of Inflammation, and Diabetic Nephropathy. Hormone and Metabolic Research, 48, 529-534.

\section{Submit or recommend next manuscript to SCIRP and we will provide best} service for you:

Accepting pre-submission inquiries through Email, Facebook, LinkedIn, Twitter, etc. A wide selection of journals (inclusive of 9 subjects, more than 200 journals)

Providing 24-hour high-quality service

User-friendly online submission system

Fair and swift peer-review system

Efficient typesetting and proofreading procedure

Display of the result of downloads and visits, as well as the number of cited articles

Maximum dissemination of your research work

Submit your manuscript at: http://papersubmission.scirp.org/

Or contact ojoph@scirp.org 